\title{
Anti-V2 Antibody Deficiency in Individuals Infected With HIV-1
}

2 Lily Liu, ${ }^{\mathrm{a},}$ Liuzhe Li, ${ }^{\mathrm{a},}$ Aubin Nanfack, ${ }^{\mathrm{b}, \mathrm{h}}$ Luzia M. Mayr, ${ }^{\mathrm{a}}$ Sonal Soni, ${ }^{\mathrm{a}}$ Adam Kohutnicki, ${ }^{\mathrm{a}}$

3 Lucy Agyingi, ${ }^{\text {b,i }}$ Xiao-Hong Wang, ${ }^{\mathrm{c}}$ Michael Tuen, ${ }^{\mathrm{a}}$ Yongzhao Shao, ${ }^{\mathrm{d}}$ Maxim Totrov, ${ }^{\mathrm{e}}$ Susan

4 Zolla-Pazner, ${ }^{\mathrm{f}}$ Xian-Peng Kong, ${ }^{\mathrm{g}}$ Ralf Duerr, ${ }^{\mathrm{a}}$ Miroslaw K. Gorny ${ }^{\text {a\# }}$

5

$6{ }^{a}$ Department of Pathology, New York University School of Medicine, New York, New York,

7 USA

$8{ }^{\mathrm{b}}$ Medical Diagnostic Center, Yaoundé, Cameroon

$9{ }^{c}$ Veterans Affairs New York Harbor Healthcare System, New York, New York, USA

$10{ }^{\mathrm{d}}$ Department of Population Health, New York University School of Medicine, New York, New

11 York, USA

12 'Molsoft, LLC, San Diego, California, USA

$13{ }^{\mathrm{f}}$ Division of Infectious Diseases, Department of Medicine, Icahn School of Medicine at Mount

14 Sinai, New York, New York, USA

$15{ }^{g}$ Department of Biochemistry and Molecular Pharmacology, New York University School of

16 Medicine, New York, New York, USA

$17{ }^{\mathrm{h}}$ Chantal Biya International Reference Center for Research on HIV/AIDS Prevention and

18 Management, Yaoundé, Cameroon

$19{ }^{\mathrm{i}}$ Faculty of Science, University of Dschang, Dschang, Cameroon

20

21 Running Head: Anti-V2 Antibody Deficiency in Individuals With HIV-1

22 \#Address correspondence to Miroslaw K. Gorny, mirek.gorny@nyumc.org

23 *Present address: Luzia M. Mayr, IQVIA, Strasbourg, France; Adam Kohutnicki, Sackler School 
24 of Graduate Biomedical Sciences, Boston, MA, USA. ${ }^{\dagger}$ These authors contributed equally.

\section{ABSTRACT}

26 The positive correlation of high levels of plasma anti-V2 antibodies (Abs) with protective

27 immunity in the Phase III anti-HIV RV144 vaccine trial generated interest in the induction of these Abs for HIV vaccine development. We analyzed plasma samples from 79 chronically

29 infected Cameroonian individuals for $\mathrm{Ab}$ reactivity against three V1V2 fusion proteins and five cyclic V2 peptides and found that HIV-1 infection induces different levels of anti-V2 Abs. While the majority of plasma samples reacted strongly with one or more V2 antigens, $10 \%$ (8) of the samples were nonreactive. Deficiency of anti-V2 Abs was consistently found in longitudinal plasma samples tested over 8 to 54 months of HIV infection. There was a strong correlation between binding activities of plasma anti-V2 Abs and anti-gp120 and anti-gp41 Abs, suggesting that deficiency of V2 Abs could be related, in part, to a limited ability to elicit strong Ab

responses. Analysis of gp120 sequences revealed that the V2 region of viruses from donors with V2-deficient versus V2-reactive Abs displayed a tendency toward longer length, more glycans, and lower isoelectric point and charge. No differences between these two patient groups were noted in the same parameters measured in the V1 region. These data suggest that immunogens containing a shorter V2 region with fewer glycosylation sites and higher electrostatic charges would be beneficial for induction of anti-V2 Abs, but the ability to mount a strong general Ab response to HIV-1 appears to be a dominant factor.

43 IMPORTANCE The results of the RV144 vaccine clinical trial showed a correlation between 44 plasma Abs against a V1V2 fusion protein and a decreased risk of acquiring HIV-1 infection.

45 This turned the focus of some HIV vaccine design to the induction of elevated levels of anti-V2 46 Abs to increase vaccine efficacy. In plasma samples from Cameroonian individuals infected with 
47 HIV-1, we observed broad variations in levels of anti-V2 Abs, and 8 of the 79 plasma samples

48 tested displayed substantial deficiency of V2 Abs. Sequence analysis of the V2 region from

49 plasma viruses and multivariate analyses of V2 characteristics showed a significant difference in

50 several features between V2-deficient and V2-reactive plasma Abs. These results suggest that

51 HIV vaccine immunogens containing a V2 region with shorter length, fewer glycosylation sites,

52 and higher electrostatic charges may be beneficial for induction of a higher level of anti-V2 Abs

53 and thus contribute to HIV vaccine efficacy.

54

55 KEYWORDS HIV-1, V1V2 region, V2 conformational antibodies, V2 linear antibodies, V2

56 antibody deficiency

57 
Anti-V2 antibodies (Abs) have been the subject of studies to determine their role in

59 protection against HIV-1 infection due to the results of the Phase III RV144 vaccine trial, which showed an inverse correlation with risk of infection (1). The RV144 data revealed that the V2 Abs in vaccinees were highly cross-clade reactive and that high levels, (but not medium or low levels) of plasma Abs against a V1V2 fusion protein correlated with reduced acquisition of HIV1 infection $(1,2)$. The V2 region contains at least 3 types of epitopes defined by anti-V2 monoclonal Abs (mAbs): i) V2 integrin (V2i), which is a conformation-dependent motif and includes the $\alpha 4 \beta 7$ integrin binding site; ii) the V2 peptide (V2p) linear epitope; and iii) the V2 quaternary (V2q) epitope, present preferentially on the trimer (3). The majority of anti-V2 Abs are specific for conformation-dependent V2i epitopes; a smaller amount to the linear V2p epitopes, and some are specific for quaternary V2q epitopes and only present in a small proportion of HIV-infected individuals.

The frequency of anti-V2 Abs in the plasma of individuals infected with HIV-1 varies among studies, depending on the methods used and the population studied. Screening of immune

72 plasma using V2 consensus peptides with the HxB2 sequence detected $12 \%$ and $21 \%$ positive

73 sera from HIV-1-infected individuals $(4,5)$. Using V1V2 proteins expressing both conformation-

74 dependent V2i and linear V2p epitopes, the frequency of plasma anti-V2 Abs is higher, yielding

$7530 \%$ and $48 \%$ in two studies $(6,7)$. The prevalence of anti-V2 Abs in clade B-infected

76 individuals was determined to be $45 \%$ when tested against a C1-V1V2 BH10 protein and $30 \%$

77 when screened in a competition assay with the $697 \mathrm{mAb}$ specific for the conformational V2i

78 epitope (8).

The frequency of anti-V2 Abs induced by the RV144 vaccine was relatively high, given 
81 sequence of subtype B strain CaseA2 (9). A high percentage of plasma samples was also reactive

82 with the cyclic V2 peptide with the sequence of clade AE 92TH023 (1). Given that the high level

of anti-V2 Abs is relevant for protection (2) and that not all immune plasma samples from infected and vaccinated individuals contain V2 Abs, we studied a panel of plasma samples to determine the frequency of anti-V2 Abs against different V1V2 fusion proteins and cyclic V2 peptides. Lack of anti-V2 Abs in some plasma samples was in part dependent on a weak general $\mathrm{Ab}$ response to HIV envelope (Env) antigens, manifested by significantly lower titers of Abs against V3, gp120, and gp41 proteins compared with plasma with reactive anti-V2 Abs. In addition, differences in the V2 region, including extended length, glycosylation sites, lower isoelectric point, and charge may also contribute to lower immunogenicity and deficiency of anti-V2 Abs in some individuals infected with HIV-1.

\section{RESULTS}

Frequency of plasma Abs against V2 and control antigens. A panel of 79 plasma samples was obtained at the Medical Diagnostic Center in Yaoundé, Cameroon from a cohort of individuals chronically infected with HIV-1. The plasma samples were screened at a 1:100 dilution by ELISA against three V1V2 fusion proteins and five biotinylated cyclic V2 peptides. Given that anti-V1 Abs are sequence-specific (10) and don't bind to heterologous V1V2 fusion proteins, plasma samples can be tested against V1V2 fusion proteins with heterologous sequence to detect specific Abs against the V2 region. To confirm that the anti-V1 Abs would not bind to heterologous V1V2 fusion proteins, we screened all plasma samples against two fusion proteins with the major parts of $\mathrm{V} 2$ deleted: $\mathrm{V} 1 \Delta \mathrm{V} 2_{\mathrm{A} 244}-\mathrm{gp} 70$ and $\mathrm{V} 1 \Delta \mathrm{V} 2_{\mathrm{CaseA} 2}-\mathrm{gp} 70$ (Table $\mathrm{S} 1$ ). None of the 79 plasma samples reacted with these two $\mathrm{V} 1 \Delta \mathrm{V} 2$ proteins, confirming that binding of plasma to heterologous V1V2 fusion proteins usually detects Abs specific for V2. 
The frequency of plasma with anti-V2 Abs varied depending on the antigen sequence.

105

106

107

108

109

110

111

112

113

114

115

116

117

118 119 below.

120

121

122

123

124

125

126 1A).

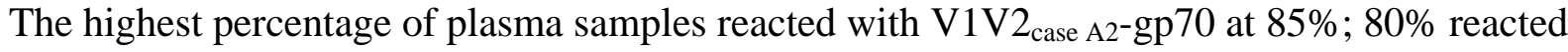
with V1V2 ${ }_{\mathrm{A} 244-\mathrm{gp} 70}$; and 53\% of plasma Abs bound to V1V2 ${ }_{\mathrm{ZM} 109^{-}}$FD6 fusion proteins (Fig. 1A). The frequency of anti-V2 peptide Abs was lower, ranging from $72 \%$ to $40 \%$ for plasma binding to $\mathrm{V} 2_{\mathrm{A} 244}, \mathrm{~V} 2_{92 \mathrm{TH} 023}$ (clade AE), V2 $2_{\text {Du422 }}$ (clade C), V2 230 and $\mathrm{V} 2_{200}$ (clade AG) (Fig.

All 79 plasma samples reacted by ELISA with gp120 ${ }_{\mathrm{A} 244}$ and gp $41_{\mathrm{MN}}$ proteins, while 76 (96\%) bound to cyclic $\mathrm{V} 3_{\mathrm{A} 244}$ peptide, most of the latter reaching the saturation level at OD 3.5 to 3.9 (Fig. 1A). The IgG subclasses and IgA of plasma Abs, tested separately against V1V2 ${ }_{\mathrm{A} 244^{-}}$ gp70, showed the dominance of IgG1 Abs, whereas IgG3 and IgA were only detected in 3 plasma samples each, and $\mathrm{IgG} 2$ and $\mathrm{IgG} 4$ binding was not detectable (Fig. 1B). The results showed a broad range of ODs for anti-V1V2 fusion proteins and anti-V2 peptides Abs, from close to 0 to 3.9, while the OD range for anti-gp120 was from 1.2 to 3.9 and for anti-gp41 from 2.1 to $3.7 \mathrm{OD}$ (all positive). This indicates a weaker immunogenicity of the V2 region compared with gp120 and gp41, which was further confirmed by $50 \%$ titers of plasma Abs, as shown

The $\mathrm{CD}^{+} \mathrm{T}$ cell counts, cells/ $\mu \mathrm{L}$, were comparable in two tested groups $(6$ samples each): V2 deficient and V2 reactive; mean counts were higher but not significant in the V2deficient group (558 vs 402, respectively; $P=0.1426$ ). Viral loads, HIV RNA copies/mL, were measured in the same plasma samples, and results in the V2-deficient and V2-reactive groups were also comparable: 7,076 vs 16,400 , respectively $(P=0.2780)$.

Glycoprotein 120 from 12 plasma viruses (6 each from the V2-deficient and V2-reactive groups) was sequenced, and virus subtypes were identified (Table 1). All but one virus (clade C) 
127

128

129

130

131

132

133

134

135

136

137

138

139

140

141

142

143

144

145

146

147

148

were HIV-1 circulating recombinant forms (CRF), which dominate in Cameroon, according to recent analysis with the most prevalent CRF02_AG $(64.9 \%)$ and CRF22_01A1 $(7.1 \%)(11,12)$.

The identified subtypes in this study were as follows: CRF02_AG (3 plasma samples), CRF01_AE (2), CRF22_01A1 (2), CRF11_cpx, CRF18_cpx, CRF36_cpx, and CRF37_cpx (Table 1).

Reactivity of plasma anti-V2 Abs. The majority of 79 plasma samples at 1:100 dilutions (90\%) were cross-reactive against eight V2 antigens including three V1V2 fusion proteins and five V2 peptides and representing sequences from HIV-1 subtypes AE, AG, B and C. Eleven plasma samples (14\%) reacted with all eight V2 antigens (Fig. 2A), while 60 plasma samples (76\%) reacted with several, but not all, V2 antigens (data not shown). Eight plasma samples (10\%) did not react with any of the eight V2 antigens (Fig. 2B) with the exception of three plasma samples which each bound weakly to one V2 antigen, but still reacted with cyclic V3 ${ }_{\mathrm{A} 244}$ peptide, gp120 244 and gp41 $1_{\mathrm{MN}}$ (Fig. 1A).

Given that plasma sample reactivity is usually tested against heterologous V2 sequences, we also included cyclic V2 peptides with sequences derived from two blood donors, MDC230 and MDC200, to test the reactivity to autologous linear V2 epitopes (Table 1). The results showed strong binding of plasma MDC230-1 (V2-reactive group) to the autologous $\mathrm{V} 2_{230}$ peptide while plasma MDC200-2 (V2-deficient group) bound only weakly to the autologous $\mathrm{V} 2_{200}$ peptide but not to other heterologous $\mathrm{V} 2$ antigens (Table 1). Of interest, the $\mathrm{V} 2_{200}$ peptide was weakly reactive with 4 of 6 plasma samples from the cross-reactive group (Table 1). One unusual feature of the $\mathrm{V} 2$ region represented by the $\mathrm{V} 2_{200}$ peptide is its exceptionally low $\mathrm{pI}$ of 4.79, while other V2 regions have pI values between 6.52 and 9.69 (Table S3). 
3). Titers of anti-V2 $2_{\mathrm{A} 244} \mathrm{Abs}$ in the V2-deficient group were undetectable (<1:100 dilution) (Fig.

cyclic V3 $3_{\mathrm{A} 244}$ peptide, gp120 ${ }_{\mathrm{A} 244}$, and gp41 $1_{\mathrm{MN}}$ in the group of V2-reactive Abs vs those with V2-

171 ) (Fig. 5). There was a strong correlation $(P<0.0001)$ between a level of Abs against V1V2 ${ }_{\mathrm{A} 244^{-}}$ 
172 gp70 versus two other V1V2 fusion proteins (CaseA2 and ZM109) and three cyclic V2 peptides

173 (A244, 92TH023, Du422), as well as gp120 ${ }_{\mathrm{A} 244}$ and gp41 $1_{\mathrm{MN}}$. Thus, correlation of low level of

174 Abs against V2 and gp120/ gp41 suggest that a deficiency of anti-V2 plasma Abs is related to a

175 generally weaker Ab response to HIV-1 Env antigens in a subset of individuals infected with

176 HIV-1.

177 Characteristics of the V2 and V1 regions. We sequenced gp120 of the viruses in

178 plasma of 12 selected patients to analyze the V2 and V1 regions, including properties that may

179 have some influence on the immunogenicity of V2. From each plasma virus, 3 to 9 gp120

180

sequences were produced and used to generate consensus sequences for all 12 subjects (Table

181

2S). We analyzed the amino acid (AA) length, number of putative N-linked glycosylation sites,

182 isoelectric point $(\mathrm{pI})$, and charge of the V2 and V1 regions. For each region, we compared these

183 features in the V2-deficient vs V2-reactive groups (Table 2, Table S3). In the V2 region, AA

184 length was significantly longer in the V2-deficient vs V2-reactive group (43.5 vs 39.5 AA;

185

186

187

188

189

190

191

192

193

194

$P=0.0338)$, while pI ( 8.47 vs $9.25 ; P=0.1075)$ and charge ( 1 vs. $2.5 ; P=0.1613)$ were lower, but

not significantly different in the V2-deficient vs the V2-reactive group, respectively (Table 3). In

contrast to these data, the V1 region displayed statistically comparable AA length of 23.5 vs 24.5

$(P=0.572)$, pI values of 4.89 vs $4.37(P=0.6991)$ and charge: 1 vs $-1.5(P=0.8068)$ (Table 3$)$.

We also analyzed the $\beta$-sheet propensity for the central conserved segment (E153 to

I184) and the $\alpha$-helix propensity (K168 to V172) of the V2 region. The $\beta$-sheet propensity

correlates with neutralization sensitivity of the virus (13) and may suggest a different

immunogenicity profile, i.e., preferential presentation of different epitopes. The $\alpha$-helix

propensity is an estimate of the helical conformation, which is recognized by anti-V2 peptide

mAbs such as CH58 (14) and putatively induces anti-V2p Abs; lower propensity suggest a 
higher tendency to form a helical structure. The two parameters were comparable between the V2-deficient and V2-reactive groups (Table 3, Table S3). Thus, the V2 consensus sequences from the V2-deficient compared with the V2-reactive group were slightly longer, with one additional $\mathrm{N}$-linked glycosylation site on average and a tendency to a lower $\mathrm{pI}$ and electrostatic charge in the V2-deficient group.

Multivariable analysis. Given that the majority of features characterizing the V2 region, except for length, are not significantly different between the V2-deficient vs V2-reactive groups, we tested whether the combination of multiple features could distinguish these two groups (Table 3). We defined composite indexes by combining 2 or 3 features to determine if the difference between the V2-deficient and V2-reactive groups, in the V2 and V1 regions, is significant, using the nonparametric Wilcoxon test. The difference between "No. AA" and "pI" and the difference between "No. AA" and "Charge" completely separated the V2-deficient from V2-reactive groups. That is, for each of the composite indexes, the maximum value (Max) in the V2-reactive group was lower than the minimum value (Min) in the V2-deficient group. Despite the small sample sizes, the lack of overlap in the values of each composite index between the two groups is statistically significant $(P=0.005)$ (Table 3). Similarly, combining three features ("the sum of No.AA and No. glycosylation sites minus pI," "the sum of No. AA and No. glycosylation sites minus charge," and "the sum of No. AA and $\alpha$-helix minus pI or charge" also separated the V2-deficient and V2-reactive groups; the non-overlapping index values between the groups are statistically significant $(P=0.005$ and 0.002 , respectively (Table 3$)$. This analysis provides evidence that multivariate predictions are more powerful than any single V2 variable for distinguishing V2-deficient from V2-reactive patient groups (Table 3). The same method was 
217

218

219

220

221

222

223

224

225

226

227

228

229

230

231

232

233

234

235

236

237

238

239

used for analysis of the V1 region as a control and did not show any significant differences between the two groups (Table 3).

\section{DISCUSSION}

The present study analyzed Abs against the V2 region in terms of their frequency and level variation in plasma samples derived from 79 Cameroonian volunteers chronically infected with HIV-1. Given that some samples were negative for anti-V2 Abs, we focused on characterization of the V2 region of these individuals' viruses to look for characteristics that might explain the deficiency of anti-V2 response. This analysis was prompted by the observation that levels of anti-V2 Abs were inversely correlated with the reduced HIV infection rate in recipients of the vaccine used in the RV144 clinical trial $(1,2)$ although levels of anti-V2 Abs measured by OD were not unusually high (9).

In the present study, the frequency of plasma anti-V2 Abs was between $53 \%$ and $85 \%$ for the three V1V2 fusion proteins and was comparable to results in the RV144 study, which reported $84 \%$ frequency, possibly due to using the same V1V2 fusion proteins for screening (9). In previous studies of sera of individuals chronically infected with HIV-1, anti-V2 Abs were detected at a much lower frequency (from $12 \%$ to $48 \%$ ), but either the V2 antigens tested were different or plasma Abs were analyzed by different methods (4-7).

The level of anti-V2 Abs showed broad variations, in contrast to a relatively high level of Abs against V3, gp120, and gp41, as measured by OD and also by 50\% titers (Fig. 1). Eight out of $79(10 \%)$ plasma samples had no reactivity to any of the six V2 antigens in longitudinal studies over 8 to 54 months, while all plasma samples reacted to gp120 and gp41 (Fig. 2C).

There was a strong correlation between ODs of plasma Abs binding to V2 antigens and to gp120/gp41 (Fig. 5). For example, plasma samples with high or low OD for gp120 and gp41 Abs 
also had high or low levels of anti-V2 Abs, respectively, suggesting that a patient's capacity to mount $\mathrm{Ab}$ responses to HIV-1, in general, is associated with the level of anti-V2 Abs.

We hypothesized that, in addition to a low Ab response to Env proteins, the lack of antiV2 Abs in several patients may depend on unusual characteristics of the V2 regions. Analysis of V2 sequences revealed that the V2 region of viruses from donors with V2-deficient versus V2reactive Abs was significantly longer $(P=0.0303)$, with 1 additional $\mathrm{N}$-linked glycosylation site, on average. Usually, a longer V2 region is accompanied by an increased number of N-linked glycosylation sites (15-17). There is a correlation between the length and number of N-linked glycosylation sites, as has been observed in 41 pseudo-typed viruses in which neutralizationsensitive viruses to anti-V2 mAbs displayed shorter length and fewer glycosylation sites (18). Given that additional glycosylation sites in the V2 region confer resistance to neutralization by $\mathrm{V} 2 \mathrm{mAbs}$, this may also have an impact on immunogenicity, resulting in weaker or lack of $\mathrm{Ab}$ response, particularly in subjects with poor humoral immune response to infecting virus. The charge and $\mathrm{pI}$ of the V2 region were also lower in the V2-deficient versus V2reactive panel of sequences (Table 3 ). Both these factors play also a role in anti-V3 mAbs; the pI of the VH CDR3 was significantly lower for human anti-V3 mAbs neutralizing Tier 2 and 3 pseudo-typed viruses vs non-neutralizing mAbs (19). For example, JR-FL.JB virus (Tier 2) was neutralized by 12 anti-V3 mAbs, and the pI of their VH CDR3 was significantly lower compared with that of 36 non-neutralizing V3 mAbs (data not shown); all these V3 mAbs were developed in our laboratory (19). Although the results do not correspond to the phenomenon of failed $\mathrm{Ab}$ response to the $\mathrm{V} 2$ region, they underline a functional role of electrostatic interactions between $\mathrm{Ab}$ and virus and, possibly, in immunologic recognition as well. 
All 4 features - length, number of N-glycosylation sites, pI, and charge - were also analyzed in the V1 region for control; there were no significant differences or tendencies in either higher or lower values between the groups with V2-deficient and V2-reactive Abs (Table 2).

267 peptides. These epitopes were defined by two human mAbs, $\mathrm{CH} 58$ and $\mathrm{CH} 59$, which were 268 generated from recipients of the vaccine used in the RV144 clinical trial (14). Both mAbs bind to 269 the helical structure of the V2 region, based on crystallographic analysis (14). The higher propensity to helical conformation in the central V2 segment (K168 to V172) in the V2-deficient

271 versus V2-reactive group, which indicates higher flexibility, may be less immunogenic (13).

For most features, changes in the V2 region were minimal for the V2-deficient and V2reactive groups; although length was significantly longer in the V2-deficient group. However,

274 multivariable analysis including combination of 2 or 3 features, for example, differences in 275 length and $\mathrm{pI}$ or charge and linear combinations of length, pI, and glycosylation sites, completely 276 separated the two groups and resulted in a highly significant difference between V2-deficient and 277 V2-reactive groups (Table 3). Thus, we conclude that the combination of these small differences 278 in multiple features may be responsible for the lower immunogenicity of the V2 region resulting 279 in lack of anti-V2 Abs in patients with significantly lower Ab response to the Env proteins. In summary, our results show a broad range of binding activity of plasma Abs against 3

281 V1V2 fusion proteins and 5 cyclic V2 peptides, with a frequency of $53 \%$ to $85 \%$, whereas in all 282 plasma samples, Abs bound to heterologous gp120 and gp41. A strong correlation between anti283 V2 and anti-gp120/ gp41 plasma Abs suggests that lack of V2 Abs depends in part on the general ability of patients to mount Ab responses to HIV-1 proteins. Sequence analysis of the V2 region 
from plasma viruses in the V2-deficient Ab group indicates that HIV vaccine immunogens containing V2 segments with fewer glycosylation sites and higher electrostatic charge may be advantageous in inducing higher titers of anti-V2 Abs.

\section{MATERIALS AND METHODS}

Ethics Statement. Blood samples from men and women infected with HIV-1 were received from the Medical Diagnostic Center (MDC), Yaoundé, Cameroon. Written informed consent forms were signed by all participants in the study and approved by the National Ethical

Review Board in Cameroon. The study has been reviewed and approved by the Institutional Review Board of New York University School of Medicine, New York, USA.

Specimens. The panel of 79 plasma samples from Cameroonian patients chronically infected with HIV-1 was randomly selected and received from the collaborative cohort shared between New York University School of Medicine, New York, NY, and the MDC, Yaoundé, Cameroon. Plasma samples were collected longitudinally over a period of 8 to 60 months and analyzed serologically. The donors were presumably infected with non-clade-B viruses, which were confirmed in 12 study subjects by sequencing their plasma viruses (Table 1). Participants enrolled in this study had been referred to the MDC in Cameroon for medical consultation due receiving an HIV-positive diagnosis. Acquisition of HIV-1 infection was self-reported as caused by heterosexual transmission in more than $95 \%$ of cases.

Recombinant proteins and peptides. Seven recombinant proteins-V1V2 $2_{\mathrm{A} 244}-\mathrm{gp} 70$

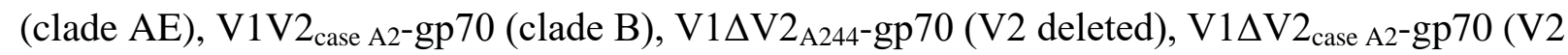
deleted), gp120 ${ }_{\mathrm{A} 244}, \mathrm{gp} 41_{\mathrm{MN}}\left(\right.$ clade B), and p24 $4_{\mathrm{HXB} 2}($ clade B) - were purchased from Immune Technology Corp., New York, NY. Biotinylated cyclic peptides —V2 ${ }_{\mathrm{A} 244}, \mathrm{~V} 2_{92 \mathrm{TH} 023}$

(CRF01_AE), V2 2 Du422 (clade C), V2230 $\left(C R F 02 \_A G\right.$, plasma virus from donor MDC230, Table 
S2) and V3 $3_{\mathrm{A} 244}$ —were purchased from Biopeptide Co., Inc., San Diego, CA. One biotinylated

cyclic peptide, V2 200 (CRF02_AG), representing the V2 sequence of plasma viruses from donor MDC200 (Table S2), was purchased from Science Exchange, Palo Alto, CA. V1V2 ZM109-1FD6 (clade C) was produced as previously described (20).

ELISA against recombinant V1V2 fusion proteins, gp120, gp41 and p24 and against biotinylated onto Immulon $2 \mathrm{Hb}$ plastic plates at a concentration of $1 \mu \mathrm{g} / \mathrm{mL}$. After overnight incubation at V1V2 fusion protein were detected using mouse mAbs against IgG subclasses and goat antihuman IgA (Southern Biotech). For screenings of plasma against biotinylated peptides, the

324 peptides were immobilized at a concentration of $1 \mu \mathrm{g} / \mathrm{mL}$ onto streptavidin-coated plates

325 (StreptaWell plates, Roche). The 50\% titers of plasma Abs were determined by measuring the dilutions of plasma required for $50 \%$ maximal binding by linear regression (23). A positive

327 reaction by a plasma sample at 1:100 dilution was defined as an OD of the mean +3 standard 328 deviations from the 6 plasma samples of healthy individuals from Cameroon, and then rounded to 1 tens digit. 
$\mathrm{CD4}^{+} \mathbf{T}$ cell counts. The $\mathrm{CD}^{+} \mathrm{T}$ cell counts were determined using the Guava EasyCD4

331

Test (Guava Technologies Inc, Hayward, CA) with 2-color direct and absolute counting of number cells per $\mu \mathrm{L}(24)$.

Viral load. Viral load was determined using Abbott m2000 Real Time HIV-1 assays according to the manufacturer's instructions (Abbott Molecular, Des Plaines, IL).

Sequencing of the virus envelope. Viruses in $500 \mu \mathrm{L}$ plasma samples were concentrated by centrifugation for $2 \mathrm{~h}, 14,000 \mathrm{rpm}$, at $15^{\circ} \mathrm{C}$ prior to RNA extraction. After removal of $360 \mu \mathrm{L}$ supernatant, the virus pellet was resuspended in the remaining $140 \mu \mathrm{L}$ supernatant by vortexing, and viral RNA was extracted using the QIAamp viral RNA mini kit (Qiagen Inc., Valencia, CA) as per manufacturer's instructions. Reverse transcription and nested PCR were performed using the SuperScript One-Step RT-PCR system with platinum Taq and Platinum PCR high-fidelity SuperMix (Invitrogen, Carlsbad, CA), respectively, as per manufacturer's instructions, to isolate a portion of $e n v(\mathrm{gp} 120+$ fragment of gp41), HXB2 region 6225-7817 ( 1600 bp). PCR products were cloned into the pCR4 TOPO cloning vector (Life Technologies, Carlsbad, CA) and transformed into One Shot TOP10 competent E. coli. Positive clones were cultured in LB $_{\text {Amp }}$ medium, and plasmids were isolated using the QIAprep Spin Miniprep kit (Qiagen Inc). Plasmids were sequenced for the insert portion using universal primers M13F/R (pCR4 TOPO). Sequence analysis and alignment was performed using DNASTAR and Clustal W (25). Consensus sequences were generated using the Los Alamos National Library program ConsensusMaker.

Statistical analysis. The nonparametric Mann-Whitney-Wilcoxon test was used for comparing OD, titers of plasma Abs, and composite indexes based on linear combinations of individual characteristics or features (Table 3). Each individual feature or characteristic of the V2 
353 region (e.g., isoelectric point, charge, number of glycosylation sites) has limited power to

354 distinguish the V2-deficient group from the V2-reactive group. However, composite indexes

355 based on simple difference or sum or linear combinations of more than 1 feature (e.g., No_AA-pI

356 in Table 3) can separate these groups. The relationship of plasma Ab binding to different

357 antigens was determined by Pearson correlation coefficient (r) with $P$ values and by linear

358 regression. Statistical analysis and graphing of the data were generated using GraphPad Prism

359 version 7 (GraphPad Software, La Jolla, CA).

360

361 


\section{ACKNOWLEDGMENTS}

363

The study was supported by NIH grants AI112546 (MKG) and AI100151 (SZP/XPK).

The authors thank the individuals with HIV-1 infection for their donation of blood samples for this study, which were collected at the Medical Diagnostic Center, Yaoundé, Cameroon. We would like to thank Dr. Michelle Ryndak for reviewing the manuscript.

L.L., L.L., A.N., L.M.M., S.S., A.K., L.A., X-H.W., M.T. and Y.S. performed research; Y.S., M.T., S.Z-P., X-P.K., R.D. and M.K.G. analyzed data; and M.K.G. wrote the paper.

\section{FIGURE LEGEND}

Figure 1 Reactivity of plasma Abs against V2 antigens and control proteins. (A) All 79 plasma samples from Cameroonian HIV-1 infected individuals were tested at 1:100 dilutions by ELISA against proteins coated at $1 \mu \mathrm{g} / \mathrm{mL}$. Antigens included: two V1V2-gp70 fusion proteins with V2 deleted (V1 $\Delta$ V2) with sequences from A244 (clade AE) and CaseA2 (clade B); three V1V2 fusion proteins: V1V2 $2_{\mathrm{A} 244}-\mathrm{gp} 70$ (clade AE), V1V2 ${ }_{\text {Case A2-gp70 (clade B) and V1V2 }}$ ZM109-1FD6 (clade C); five biotinylated cyclic V2 peptides with sequences from A244 (clade AE), TH023 (clade AE), Du422 (clade C), 230 and 200 (clade AG); one biotinylated cyclic V3 ${ }_{\mathrm{A} 244}$ peptide, gp120 244 protein and gp41 $\mathrm{MN}$ protein. Percentage of plasma samples with specific anti-V2 Abs is shown below each antigen. Statistical significance between Abs against V2 and control 
antigens was determined by nonparametric Mann-Whitney test. The shape of the distribution is shown by a box with the ends of the box representing the 5th and 95th percentile, and the median marked by a horizontal line inside the box. (B) IgG subclasses and IgA of plasma Abs binding to $\mathrm{V} 1 \mathrm{~V} 2_{\mathrm{A} 244}-\mathrm{gp} 70$ fusion protein.

Figure 2 Cross-reactivity of plasma Abs with eight V2 antigens. (A) Eleven Cameroonian plasma samples (out of 79) at dilution 1:100 tested by ELISA demonstrate binding to all eight V2 antigens: V1V2A244-gp70 (clade AE), V1V2 ${ }_{\text {CaseA2-gp70 (clade B), V1V2 }}$ ZM109-1FD6 (clade C), and biotinylated cyclic $\mathrm{V} 2_{\mathrm{A} 244}, \mathrm{~V} 2_{\mathrm{TH} 023}$, (clade $\left.\mathrm{AE}\right), \mathrm{V} 2_{\mathrm{Du} 422}$ (clade $\mathrm{C}$ ), $\mathrm{V} 2_{230}$ and $\mathrm{V} 2_{200}$ (clade AG) peptides. (B) Eight plasma samples did not bind to V2 antigens tested with the exception of three plasma samples which each bound weakly to one V2 peptide. All plasma samples displayed reactivity with gp $120_{\mathrm{A} 244}$ and gp41 $\mathrm{MN}$ (Fig.1). The dashed lines indicate the 396 cutoff (mean OD $+3 x$ SD of normal human plasma).

397 Figure 3 Titers of anti-V2 and control Abs in sequential plasma samples. (A) Six donors with 398 lack of anti-V2 Abs over 11 to 54 months of observation, and (B) six donors with cross-reactive 399 anti-V2 Abs over 28 to 60 months. The 50\% titers of plasma Abs were determined by ELISA 400 against V1V2 ${ }_{\mathrm{A} 244}-\mathrm{gp} 70$ (clade $\mathrm{AE}$ ) protein, biotinylated cyclic V3 ${ }_{\mathrm{A} 244}$ peptide, gp120 ${ }_{\mathrm{A} 244}$,

$401 \mathrm{gp} 41_{\mathrm{MN}}\left(\right.$ clade B), and p24 $4_{\mathrm{HXB} 2}$ (clade B) protein. The antigens were coated or immobilized onto 402 plate at $1 \mu \mathrm{g} / \mathrm{mL}$; plasma were diluted by 10-fold dilutions starting from 1:100 to 1:1,000,000.

403 Figure 4 Titers of plasma Abs from HIV-1 infected individuals against HIV-1 antigens, V1V2, 404 V3, gp120, gp41 and p24; two groups of plasma were compared: with non-V2-reactive (crossed 405 circles) and cross-reactive anti-V2 Abs (open circles). The 50\% titers of plasma Abs were 
determined by ELISA at five serial 10-fold dilutions starting from 1:100. Statistical significance was determined by nonparametric Mann-Whitney test.

Figure 5 Correlation between binding activities (OD) of plasma Abs against V1V2 ${ }_{\mathrm{A} 244}$-gp70 (V1V2 $\left.{ }_{\mathrm{A} 244}\right)$ and other Env antigens. Plasma binding activity to V1V2 ${ }_{\mathrm{A} 244}$ was correlated with: A) V1V2 ${ }_{\text {CaseA2-gp70; B) V1V2 }} 2_{\text {ZM109-1FD6; C) V2 }} 2_{\text {A244 }}$ peptide; D) V2 $2_{\text {TH023 }}$ peptide; E) V2 $2_{\text {Du422 }}$ peptide; F) gp120 ${ }_{\mathrm{A} 244}$; G) gp41 $1_{\mathrm{MN}}$, but not with H) V3 $3_{\mathrm{A} 244}$ peptide. Correlation was determined by Pearson correlation coefficient (r) and by linear regression with $\mathrm{P}$ values.

\section{REFERENCES}

1. Haynes BF, Gilbert PB, McElrath MJ, Zolla-Pazner S, Tomaras GD, Alam SM, Evans DT, Montefiori DC, Karnasuta C, Sutthent R, Liao HX, DeVico AL, Lewis GK, Williams C, Pinter A, Fong Y, Janes H, DeCamp A, Huang Y, Rao M, Billings E, Karasavvas N, Robb ML, Ngauy V, de Souza MS, Paris R, Ferrari G, Bailer RT, Soderberg KA, Andrews C, Berman PW, Frahm N, De Rosa SC, Alpert MD, Yates NL, Shen X, Koup RA, Pitisuttithum P, Kaewkungwal J, Nitayaphan S, Rerks-Ngarm S, Michael NL, Kim JH. 2012. Immune-correlates analysis of an HIV-1 vaccine efficacy trial. N Engl J Med 366:1275-86.

2. Zolla-Pazner S, deCamp A, Gilbert PB, Williams C, Yates NL, Williams WT, Howington R, Fong Y, Morris DE, Soderberg KA, Irene C, Reichman C, Pinter A, Parks R, Pitisuttithum P, Kaewkungwal J, Rerks-Ngarm S, Nitayaphan S, Andrews C, O'Connell RJ, Yang ZY, Nabel GJ, Kim JH, Michael NL, Montefiori DC, Liao HX, Haynes BF, 
Tomaras GD. 2014. Vaccine-induced IgG antibodies to V1V2 regions of multiple HIV-1 subtypes correlate with decreased risk of HIV-1 infection. PLoS One 9:e87572.

429 3. Spurrier B, Sampson J, Gorny MK, Zolla-Pazner S, Kong XP. 2014. Functional implications of the binding mode of a human conformation-dependent V2 monoclonal antibody against HIV. J Virol 88:4100-12.

432 4. McKeating JA, Shotton C, Cordell J, Graham S, Balfe P, Sullivan N, Charles M, Page M, Bolmstedt A, Olofsson S, Kayman SC, Wu Z, Pinter A, Dean C, Sodroski J, Weiss RA. 1993. Characterization of neutralizing monoclonal antibodies to linear and conformationdependent epitopes within the first and second variable domains of human immunodeficiency virus type 1 gp120. J Virol 67:4932-4944.

437 5. Moore JP, Sattentau QJ, Yoshiyama H, Thali M, Charles M, Sullivan N, Poon SW, Fung MS, Traincard F, Pinkus M, al. e. 1993. Probing the structure of the V2 domain of human immunodeficiency virus type 1 surface glycoprotein gp120 with a panel of eight monoclonal antibodies: human immune response to the V1 and V2 domains. J Virol

6. McKeating JA, Shotton C, Jeffs S, Palmer C, Hammond A, Lewis J, Oliver K, May J, Balfe P. 1996. Immunogenicity of full length and truncated forms of the human 444 immunodeficiency virus type I envelope glycoprotein. Immunol Letters 51:101-105. 445 7. Kayman SC, Wu Z, Revesz K, Chen H, Kopelman R, Pinter A. 1994. Presentation of native epitopes in the V1/V2 and V3 regions of human immunodeficiency virus type 1 gp120 by fusion glycoproteins containing isolated gp120 domains. J Virol 68:400-10. 
8. Israel ZR, Gorny MK, Palmer C, McKeating JA, Zolla-Pazner S. 1997. Prevalence of a V2 epitope in clade B primary isolates and its recognition by sera from HIV-1-infected individuals. AIDS 11:128-30.

9. Zolla-Pazner S, deCamp AC, Cardozo T, Karasavvas N, Gottardo R, Williams C, Morris DE, Tomaras G, Rao M, Billings E, Berman P, Shen X, Andrews C, O'Connell RJ, Ngauy V, Nitayaphan S, de Souza M, Korber B, Koup R, Bailer RT, Mascola JR, Pinter A, Montefiori D, Haynes BF, Robb ML, Rerks-Ngarm S, Michael NL, Gilbert PB, Kim JH. 2013. Analysis of V2 antibody responses induced in vaccinees in the ALVAC/AIDSVAX HIV-1 vaccine efficacy trial. PLoS One 8:e53629.

10. He Y, Honnen WJ, Krachmarov CP, Burkhart M, Kayman SC, Corvalan J, Pinter A. 2002. Efficient isolation of novel human monoclonal antibodies with neutralizing activity against HIV-1 from transgenic mice expressing human Ig loci. J Immunol 169:595-605.

11. Courtney CR, Agyingi L, Fokou A, Christie S, Asaah B, Meli J, Ngai J, Hewlett I, Nyambi PN. 2016. Monitoring HIV-1 Group M Subtypes in Yaounde, Cameroon Reveals Broad Genetic Diversity and a Novel CRF02_AG/F2 Infection. AIDS Res Hum Retroviruses 32:381-5.

12. Nanfack AJ, Redd AD, Bimela JS, Ncham G, Achem E, Banin AN, Kirkpatrick AR, Porcella SF, Agyingi LA, Meli J, Colizzi V, Nadas A, Gorny MK, Nyambi PN, Quinn TC, Duerr R. 2017. Multimethod Longitudinal HIV Drug Resistance Analysis in Antiretroviral-Therapy-Naive Patients. J Clin Microbiol 55:2785-2800.

13. Totrov M. 2014. Estimated secondary structure propensities within V1/V2 region of HIV gp120 are an important global antibody neutralization sensitivity determinant. PLoS One 9:e94002. 
471 14. Liao HX, Bonsignori M, Alam SM, McLellan JS, Tomaras GD, Moody MA, Kozink

472

473

474

475

476

477

478

479

480

481

482

483

484

485

486

487

488

489

490

491

492

493

DM, Hwang KK, Chen X, Tsao CY, Liu P, Lu X, Parks RJ, Montefiori DC, Ferrari G, Pollara J, Rao M, Peachman KK, Santra S, Letvin NL, Karasavvas N, Yang ZY, Dai K, Pancera M, Gorman J, Wiehe K, Nicely NI, Rerks-Ngarm S, Nitayaphan S, Kaewkungwal J, Pitisuttithum P, Tartaglia J, Sinangil F, Kim JH, Michael NL, Kepler

TB, Kwong PD, Mascola JR, Nabel GJ, Pinter A, Zolla-Pazner S, Haynes BF. 2013. Vaccine induction of antibodies against a structurally heterogeneous site of immune pressure within HIV-1 envelope protein variable regions 1 and 2. Immunity 38:176-86.

15. Owens GP, Winges KM, Ritchie AM, Edwards S, Burgoon MP, Lehnhoff L, Nielsen K, Corboy J, Gilden DH, Bennett JL. 2007. VH4 gene segments dominate the intrathecal humoral immune response in multiple sclerosis. J Immunol 179:6343-51.

16. Sagar M, Wu X, Lee S, Overbaugh J. 2006. Human immunodeficiency virus type 1 V1V2 envelope loop sequences expand and add glycosylation sites over the course of infection, and these modifications affect antibody neutralization sensitivity. J Virol 80:9586-98.

17. van Gils MJ, Bunnik EM, Boeser-Nunnink BD, Burger JA, Terlouw-Klein M, Verwer N, Schuitemaker H. 2011. Longer V1V2 Region with Increased Number of Potential NLinked Glycosylation Sites in the HIV-1 Envelope Glycoprotein Protects against HIVSpecific Neutralizing Antibodies. J Virol 85:6986-95.

18. Gorny MK, Pan R, Williams C, Wang XH, Volsky B, O'Neal T, Spurrier B, Sampson JM, Li L, Seaman MS, Kong XP, Zolla-Pazner S. 2012. Functional and immunochemical cross-reactivity of V2-specific monoclonal antibodies from human immunodeficiency virus type 1-infected individuals. Virology 427:198-207. 
494 19. Li L, Wang XH, Williams C, Volsky B, Steczko O, Seaman MS, Luthra K, Nyambi P, 495 Nadas A, Giudicelli V, Lefranc MP, Zolla-Pazner S, Gorny MK. 2015. A broad range of mutations in HIV-1 neutralizing human monoclonal antibodies specific for V2, V3, and

498 the CD4 binding site. Mol Immunol 66:364-374.

20. Jiang X, Totrov M, Li W, Sampson JM, Williams C, Lu H, Wu X, Lu S, Wang S, ZollaPazner S, Kong XP. 2016. Rationally Designed Immunogens Targeting HIV-1 gp120 V1V2 Induce Distinct Conformation-Specific Antibody Responses in Rabbits. J Virol 90:11007-11019.

502

21. Musich T, Li L, Liu L, Zolla-Pazner S, Robert-Guroff M, Gorny MK. 2017. Monoclonal Antibodies Specific for the V2, V3, CD4-Binding Site, and gp41 of HIV-1 Mediate Phagocytosis in a Dose-Dependent Manner. J Virol 91:e02325-16.

22. Hessell AJ, McBurney S, Pandey S, Sutton W, Liu L, Li L, Totrov M, Zolla-Pazner S, Haigwood NL, Gorny MK. 2016. Induction of neutralizing antibodies in rhesus macaques using V3 mimotope peptides. Vaccine 34:2713-21.

23. Gorny MK, VanCott TC, Williams C, Revesz K, Zolla-Pazner S. 2000. Effects of oligomerization on the epitopes of the Human Immunodeficiency Virus Type 1 envelope glycoproteins. Virology 267:220-228.

24. Pattanapanyasat K, Phuang-Ngern Y, Lerdwana S, Wasinrapee P, Sakulploy N, Noulsri E, Thepthai C, McNicholl JM. 2007. Evaluation of a single-platform microcapillary flow cytometer for enumeration of absolute CD4+ T-lymphocyte counts in HIV-1 infected Thai patients. Cytometry B Clin Cytom 72:387-96. 
515 25. di Marzo Veronese F, Willis AE, Boyer-Thompson C, Appella E, Perham RN. 1994.

516 Structural mimicry and enhanced immunogenicity of peptide epitopes displayed on filamentous bacteriophage. The V3 loop of HIV-1 gp120. J Mol Biol 243:167-72. 
TABLE 1 Infecting HIV clades and ELISA reactivity of plasma antibodies to Env antigens of patients with and without V2 antibodies

\begin{tabular}{|c|c|c|c|c|c|c|c|c|c|c|c|c|}
\hline $\begin{array}{c}\text { MDC } \\
\text { donors }\end{array}$ & HIV-1 & $\begin{array}{c}\mathrm{V} 1 \mathrm{~V} 2^{1} \\
\mathrm{~A} 244 \\
\mathrm{AE} \\
\end{array}$ & $\begin{array}{c}\mathrm{V} 1 \mathrm{~V} 2^{1} \\
\text { CaseA2 } \\
\text { B }\end{array}$ & $\begin{array}{c}\text { V1V2 }{ }^{1} \\
\text { ZM109 } \\
\text { C } \\
\end{array}$ & $\begin{array}{c}\text { V2pept }^{2} \\
\text { A244 } \\
\text { AE } \\
\end{array}$ & $\begin{array}{c}\text { V2pept } \\
\text { TH023 } \\
\text { AE }\end{array}$ & $\begin{array}{c}\text { V2pept } \\
\text { Du422 } \\
\text { C }\end{array}$ & $\begin{array}{c}\text { V2pept }{ }^{2,3} \\
230 \\
\text { AG }\end{array}$ & $\begin{array}{c}\text { V2pept }{ }^{2,3} \\
200 \\
\text { AG }\end{array}$ & $\begin{array}{c}\text { V3pept } \\
\text { A244 } \\
\text { AE }\end{array}$ & $\begin{array}{c}\text { gp120 } \\
\text { A244 } \\
\text { AE }\end{array}$ & $\begin{array}{c}\text { gp41 } \\
\text { MN } \\
\text { B }\end{array}$ \\
\hline $001-4$ & CRF18_cpx & 3.2 & 3.1 & 2.0 & 3.5 & 3.5 & 3.5 & 3.5 & 0.3 & 3.6 & 3.9 & 2.9 \\
\hline $230-1$ & CRF02_AG & 3.6 & 3.5 & 2.4 & 3.6 & 2.9 & 3.5 & 3.5 & 0.8 & 3.5 & 3.2 & 3.4 \\
\hline $6501-6$ & CRF02_AG & 3.5 & 2.2 & 3.6 & 3.5 & 2.2 & 3.0 & 2.1 & 1.3 & 3.1 & 3.5 & 2.9 \\
\hline $237-2$ & CRF11_cpx & 2.4 & 3.3 & 2.2 & 3.6 & 1.9 & 1.4 & 0.7 & 1.6 & 3.6 & 4.0 & 3.2 \\
\hline $060-2$ & CRF36_cpx & 2.6 & 3.3 & 2.5 & 2.6 & 1.1 & 1.7 & 2.3 & 0.8 & 3.6 & 3.3 & 3.5 \\
\hline $221-2$ & CRF01_AE & 2.1 & 2.3 & 2.2 & 3.3 & 1.9 & 3.0 & 3.0 & 0.4 & 3.7 & 3.8 & 3.3 \\
\hline $014-2$ & $\mathrm{C}$ & 0.4 & 0.5 & 0.5 & 0.4 & 0.7 & 0.3 & 0.4 & 0.2 & 1.5 & 1.7 & 2.6 \\
\hline 019-3 & CRF22_01A1 & 0.2 & 0.2 & 0.4 & 0.2 & 0.3 & 0.3 & 0.3 & 0.1 & 3.8 & 1.8 & 3.0 \\
\hline $122-3$ & CRF01_AE & 0.5 & 0.3 & 0.2 & 0.3 & 0.2 & 0.2 & 0.3 & 0.2 & 3.6 & 3.9 & 3.5 \\
\hline $195-3$ & CRF37_cpx & 0.4 & 0.2 & 0.2 & 1.0 & 0.2 & 0.5 & 0.1 & 0.1 & 3.8 & 3.4 & 3.2 \\
\hline $200-2$ & CRF02_AG & 0.1 & 0.2 & 0.3 & 0.3 & 0.3 & 0.5 & 0.3 & 1.4 & 2.9 & 3.2 & 3.4 \\
\hline 211-1 & CRF22_01A1 & 0.3 & 0.4 & 0.4 & 0.3 & 0.2 & 0.2 & 0.3 & 0.1 & 3.0 & 3.0 & 3.3 \\
\hline
\end{tabular}

${ }^{1} \mathrm{~V} 1 \mathrm{~V} 2$ - V1V2 fusion protein, HIV-1 strain and subtype; ${ }^{2} \mathrm{~V} 2$ and V3pept. - biotinylated cyclic peptides; ${ }^{3} \mathrm{~V} 2$ peptides with sequences

from virus of donor's plasma: MDC230-1 and MDC200-2 (this allows testing of two plasma Abs vs. autologous antigens). Plasma

samples were screened by standard ELISA at 1:100 dilution against antigens coated at $1 \mu \mathrm{g} / \mathrm{mL}$; biotinylated cyclic V2 and V3

peptides were immobilized at $1 \mu \mathrm{g} / \mathrm{mL}$ on the streptavidin coated plates. The values bold are above cutoff (mean OD of 6 control

healthy plasma samples +3 standard deviation). 
TABLE 2 Titers of plasma Abs, CD4 ${ }^{+}$T cells, and viral load in two groups of HIV-1 infected subjects with anti-V2 deficient and cross-reactive Abs

\begin{tabular}{|c|c|c|c|}
\hline Features & $\begin{array}{c}\text { V2 deficient } \\
n=6\end{array}$ & $\begin{array}{c}\text { V2 cross-reactive } \\
n=6\end{array}$ & P value ${ }^{3}$ \\
\hline \multicolumn{4}{|c|}{$50 \%$ Titer $^{4}$} \\
\hline Anti-V1V2 $2_{\text {A244 }}$ & 0.0 & 50,270 & $<0.0001$ \\
\hline Anti-V33 ${ }_{\text {A244 }}$ & 3,252 & 40,572 & $<0.0001$ \\
\hline Anti-gp $120_{\mathrm{A} 244}$ & 2,438 & 70,241 & $<0.0001$ \\
\hline Anti-gp41 $41_{\mathrm{MN}}$ & 36,444 & 413,169 & $<0.0001$ \\
\hline Anti-p2 $4_{\mathrm{HXB} 2}$ & 44,696 & 72,451 & 0.0781 \\
\hline \multicolumn{4}{|c|}{$\mathrm{CD4}^{+} \mathrm{T}$ cells, $\mathrm{VL}$} \\
\hline $\mathrm{CD}^{+}{ }^{+} \mathrm{T}$ cell count & 558 & 402 & 0.1426 \\
\hline Viral load (VL) & 7,076 & 16,400 & 0.2780 \\
\hline
\end{tabular}

${ }^{1}$ Panel of plasma with undetectable anti-V2 Abs; ${ }^{2}$ Panel of plasma with cross-reactive anti-V2 Abs; ${ }^{3}$ nonparametric Mann-Whitney test; ${ }^{4}$ mean of $50 \%$ titers. 
TABLE 3 Characteristics of the V2 and V1 regions in HIV-infected individual who were had V2-deficient antibody responses or cross-reactive antibody response

\begin{tabular}{|c|c|c|c|c|c|c|}
\hline \multirow{3}{*}{ Features } & \multicolumn{2}{|c|}{ V2 region } & \multirow{3}{*}{$\mathbf{P}^{1}$} & \multicolumn{2}{|c|}{ V1 region } & \multirow{3}{*}{$\mathbf{P}^{1}$} \\
\hline & V2 Deficient Group & V2 Cross Group & & V2 Deficient Group & V2 Cross Group & \\
\hline & Median & $(\min , \max )$ & & \multicolumn{2}{|r|}{$(\min , \max )$} & \\
\hline \# amino acids (AA) & $43.5(40,58)$ & $39.5(37,41)$ & 0.034 & $23.5(22,32)$ & $24.5(21,38)$ & 0.572 \\
\hline \# glycosylation sites & $2(2,7)$ & $2(0,2)$ & 0.115 & $3(2,4)$ & $2.5(1,4)$ & 0.452 \\
\hline $\mathrm{pI}$ & $8.47(4.79,9.66)$ & $9.25(6.52,9.69)$ & 0.108 & $4.89(3.88,9.37$ & $4.37(3.99,9.58)$ & 0.699 \\
\hline Charge & $1(-1,3)$ & $2.5(0,3)$ & 0.161 & $-1(-3,2)$ & $-1.5(-4,2)$ & 0.807 \\
\hline$\alpha$-helix K168-V172 & $1.78(1.6,1.9)$ & $1.57(1.13,2)$ & 0.376 & nt & nt & nt \\
\hline$\beta$-sheet E153-I184 & $-19.82(-22,-16.3)$ & $-20.32(-22.97,-18.88)$ & 0.699 & $\mathrm{nt}$ & $\mathrm{nt}$ & $\mathrm{nt}$ \\
\hline \multicolumn{7}{|c|}{ Composite Indexes* } \\
\hline 1. AA-pI & $35.37(31.98,49.5)$ & $30.89(27.87,31.75)$ & 0.005 & $18.07(13.63,26.4)$ & $18.74(14.42,34.0)$ & 1.000 \\
\hline 2. AA-Charge & $42(40,56)$ & $37.5(35,39)$ & 0.005 & $24.5(21,33)$ & $25.5(22,42)$ & 0.748 \\
\hline 3. AA-pI+ Glyc. & $37.37(33.98,56.5)$ & $32.39(27.87,33.75)$ & 0.005 & $20.44(16.63 .30 .4)$ & $21.74(15.42,38)$ & 1.000 \\
\hline 4. AA-pI- Glyc. & $33.37(29.98,42.5)$ & $29.39(26.31,29.75)$ & 0.005 & $16.07(10.63,22.4)$ & $15.74(13.42,30)$ & 1.000 \\
\hline 5. AA-Charge+Glyc. & $44(42,63)$ & $39(35,41)$ & 0.005 & $27(24,37)$ & $28.5(23,46)$ & 0.936 \\
\hline 6. AA-Charge-Glyc. & $40(38,49)$ & $36(33,37)$ & 0.005 & $22.5(18,29)$ & $22.5(20,38)$ & 0.808 \\
\hline 7. AA-pI+helix & $37.2(33.76,51.4)$ & $32.39(29.44,33.7)$ & 0.002 & $\mathrm{nt}$ & $\mathrm{nt}$ & nt \\
\hline 8. AA-Charge+helix & $43.82(41.6,57.9)$ & $38.99(36.57,40.13)$ & 0.002 & $\mathrm{nt}$ & $\mathrm{nt}$ & $\mathrm{nt}$ \\
\hline
\end{tabular}

${ }^{1} \mathrm{P}$ value, V2 deficient versus cross-reactive group (non-paired tests), Wilcoxon test; nt - not tested.

*Composite indexes are based on difference or sum or linear combinations of more than one features; 1. \# AA-pI; 2. \# AA-Charge; 3. \# AA-pI+ \# glycosylation sites; 4. \# AA-pI - \# glycosylation sites; 5. \# AA-Charge+\# glycosylation sites;

6. \# AA-Charge-\# glycosylation sites; 7. \# AA-pI+ $\alpha$-helix propensity; 8. \# AA-Charge+ $+\alpha$-helix propensity. 


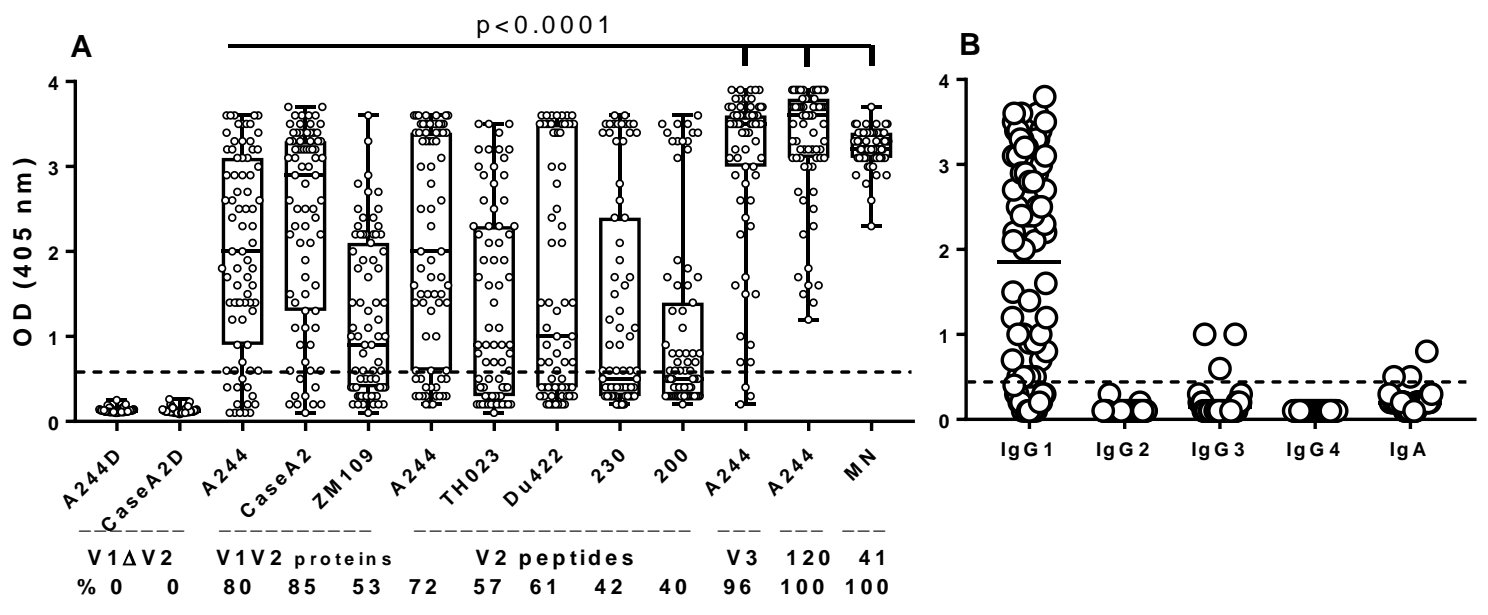

\section{FIG 1}



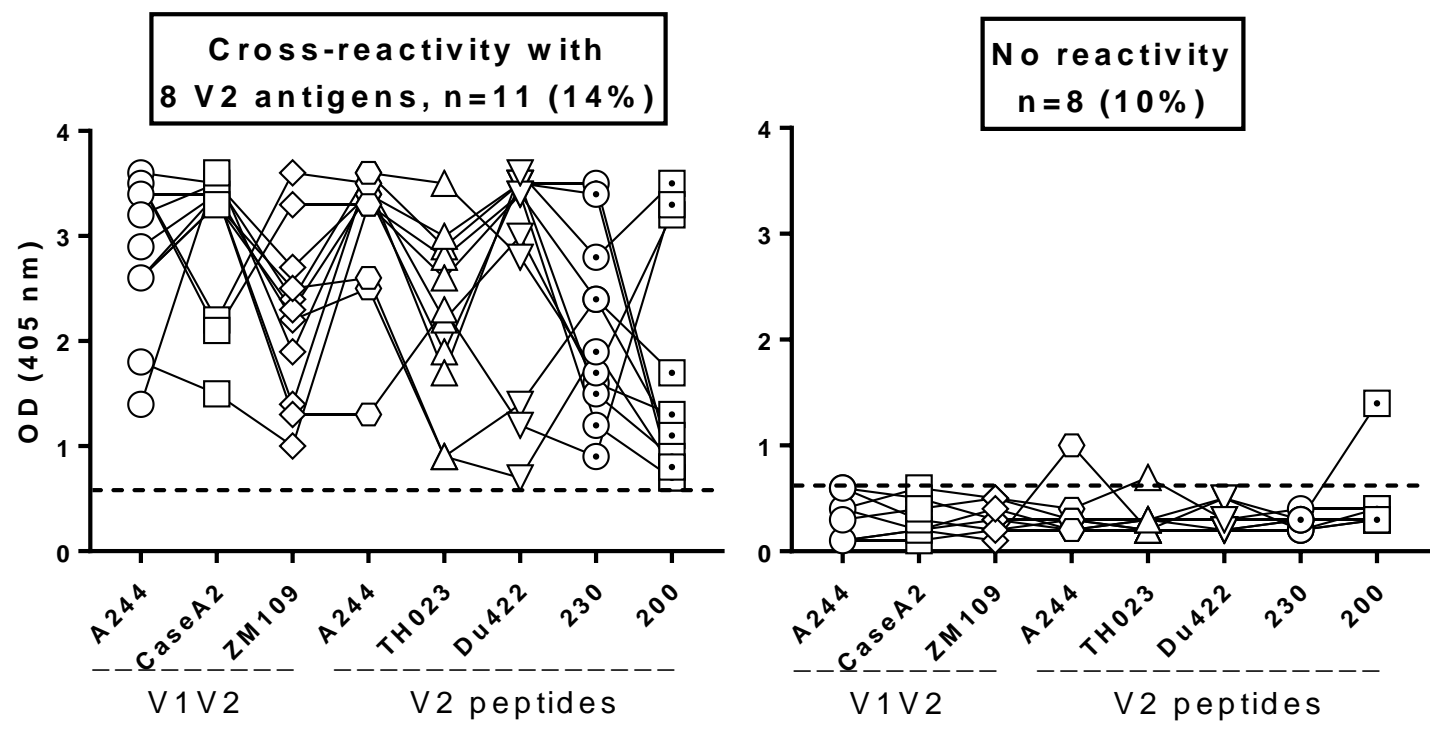

FIG 2 

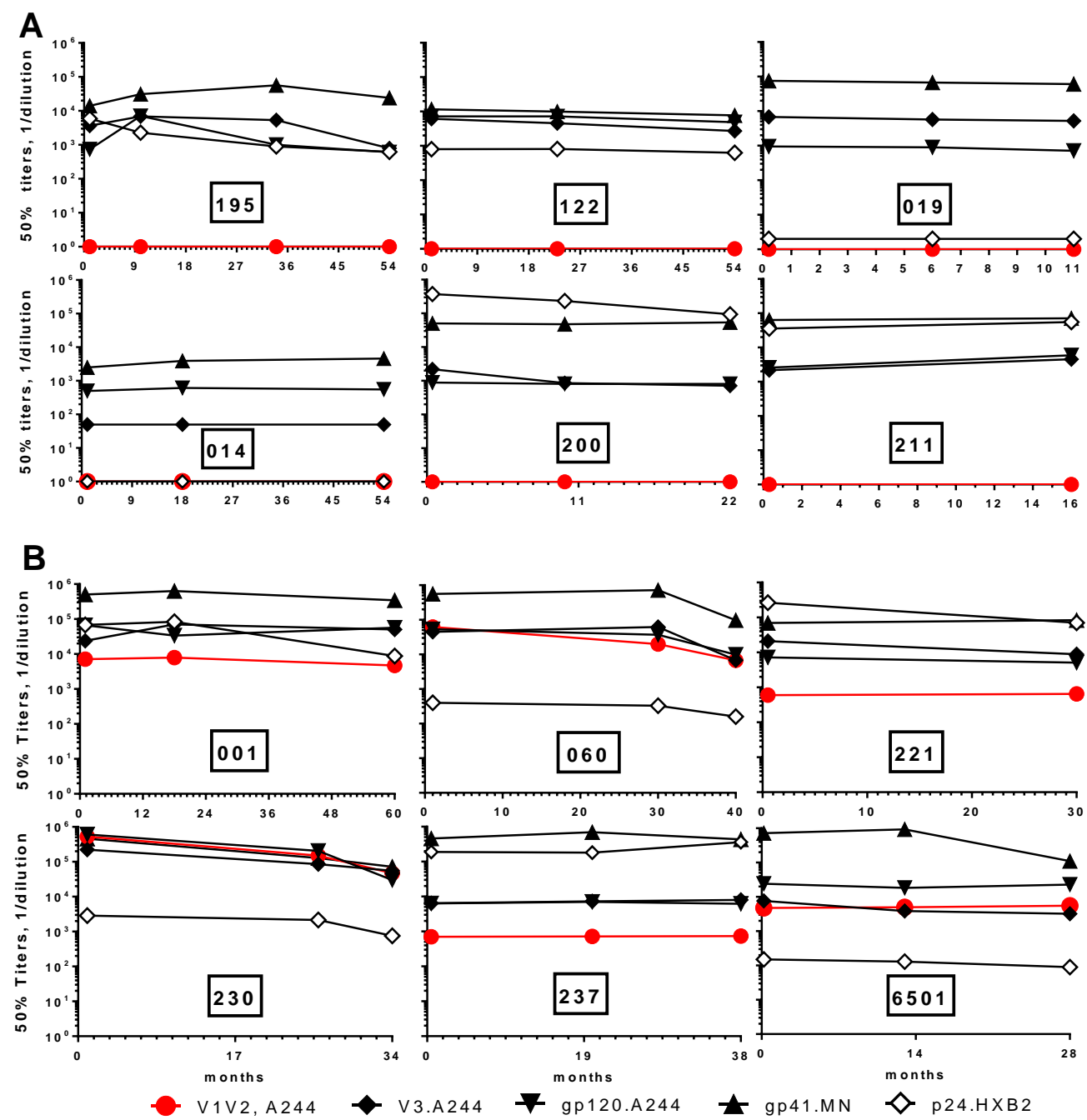

\section{FIG 3}




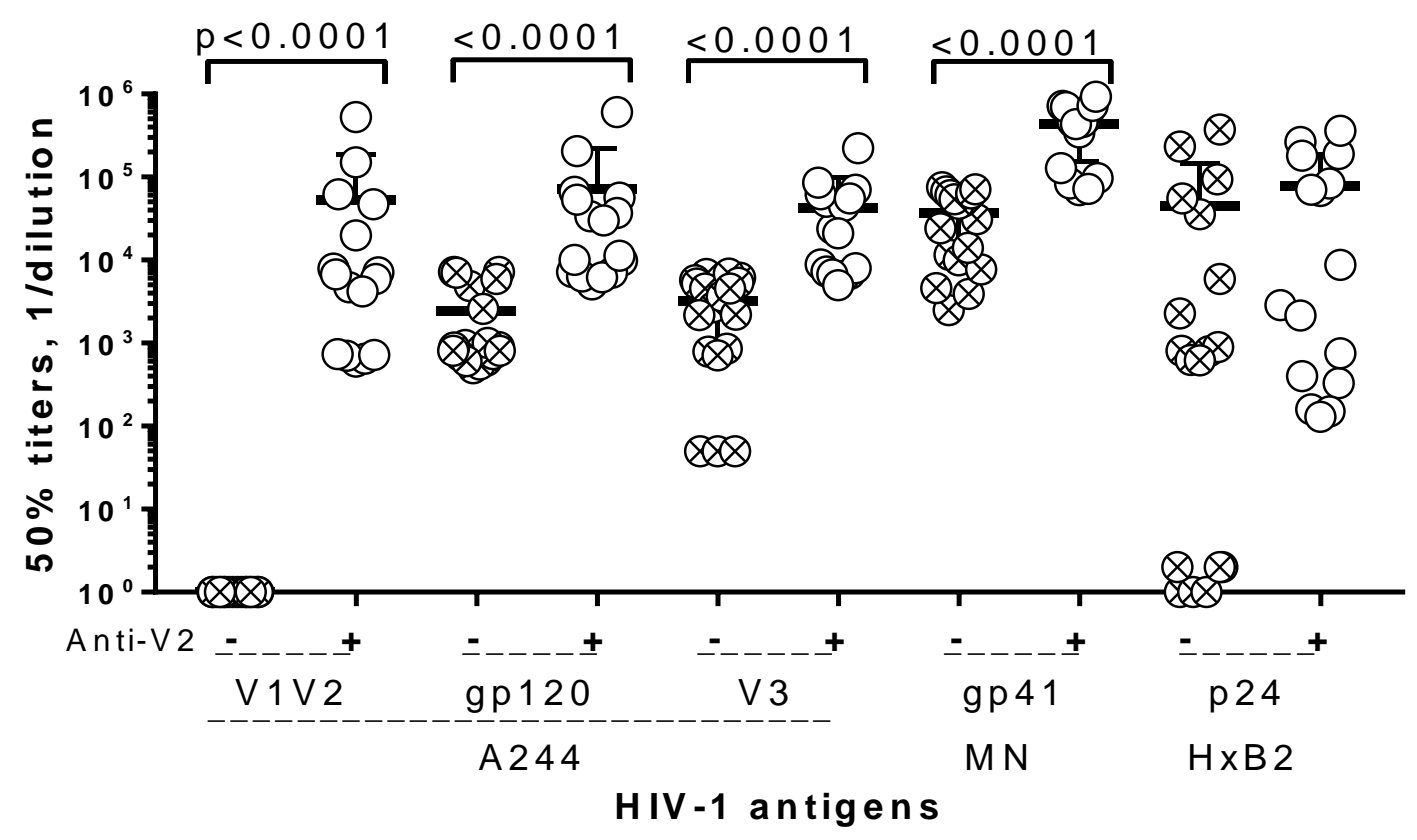

\section{FIG 4}



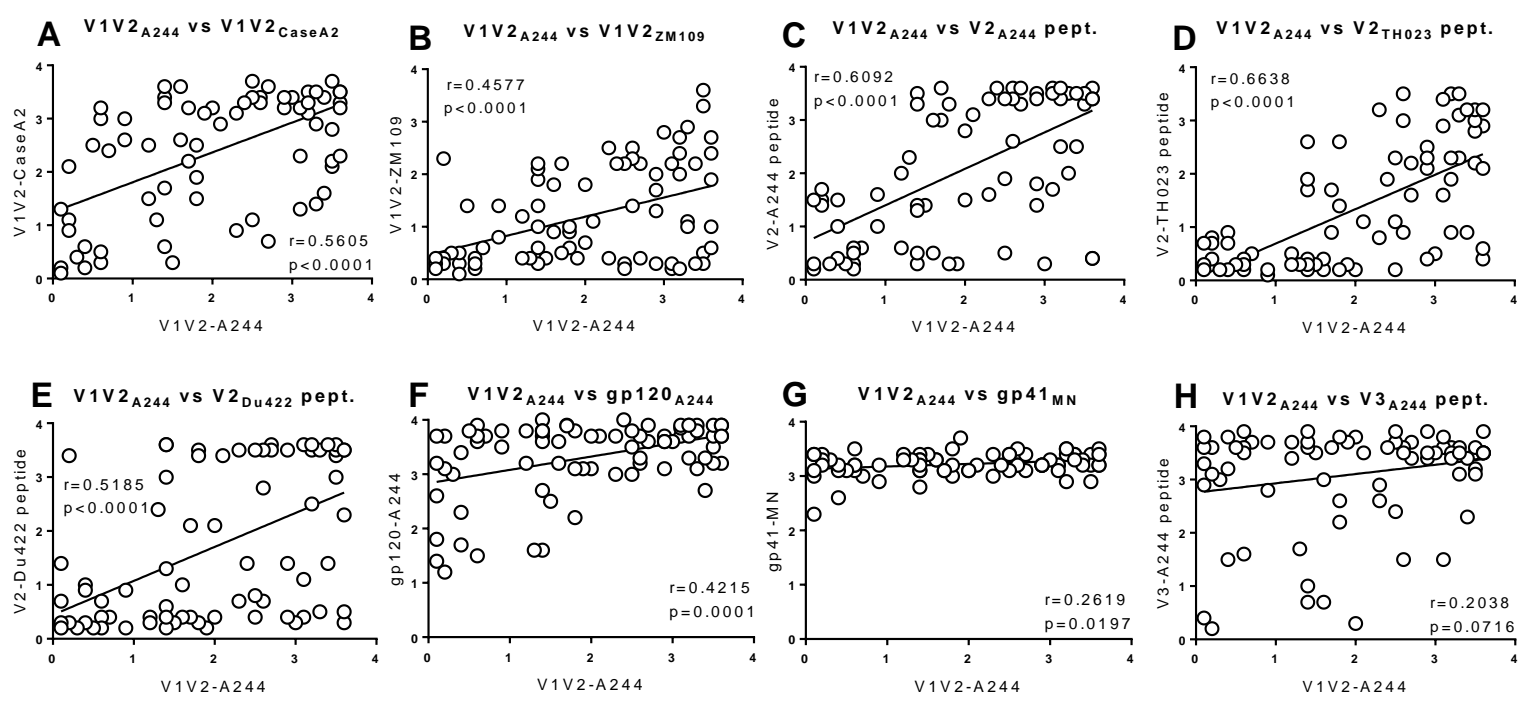

\section{FIG 5}

